\title{
An acellular dermal matrix allograft for treatment of multiple gingival recession defects: a case report
}

\begin{abstract}
Root coverage is indicated for esthetics improvement, proper plaque control and root hypersensitivity management. Several techniques have been developed for obtaining predictable and esthetic root coverage. An acellular dermal matrix allograft (Alloderm) was introduced in periodontal surgery as a palatal donor substitute. This regenerative tissue matrix has been used as a donor material for root coverage procedures. This case report describes a surgical technique where an Alloderm was used to treat multiple gingival recession's defects. The results from the study indicated that Alloderm with coronally positioned flap can be successfully used for root coverage.
\end{abstract}

Keywords: acellular dermal matrix graft, alloderm; gingival recession, root coverage, connective tissue graft
Volume 9 Issue I - 2018

\section{Fatemah Mohammad AIAhmari}

Department of Periodontics and Community Dentistry, King Saud University, Saudi Arabia

Correspondence: Fatemah Mohammad AIAhmari, Department of Periodontics and Community Dentistry, King Saud University, Riyadh, Saudi Arabia, Tel 0096655 I 234955,

Email falahmari@ksu.edu.sa

Received: January 14, 2018 | Published: January 25, 2018
Abbreviations: Alloderm, an acellular dermal matrix allograft; CAL, clinical attachment level

\section{Introduction}

Gingival recession is the exposure of root surface due to the apical migration of gingival tissue margins. Root coverage is indicated for esthetics improvement, ${ }^{1}$ proper plaque control ${ }^{2}$ and root hypersensitivity management. 3 Several techniques have been developed to obtain predictable and esthetic root coverage. ${ }^{4-7}$ Subepithelial connective tissue graft is considered as the gold standard in grafting procedures. The disadvantage of this procedure is the morbidity associated with the second surgical site where the palatal donor tissue gets harvested. If the patient has inadequate amount of palatal tissues, it would be difficult to harvest sufficient volume of donor tissue. Hence alternate method for root coverage has been introduced, to eliminate the need for a second surgical site. Acellular dermal matrix allografts (Alloderm) were introduced in periodontal surgery as a substitute to palatal donor. Alloderm are donated human dermis, which are comprised of a structurally integrated basement membrane complex and an extracellular matrix. ${ }^{8}$ These allografts were prepared by removing all epidermal and dermal cells that could lead to disease transmission and immunogenic reaction. ${ }^{9,10}$ Alloderm has been used successfully as donor material for root coverage procedures with a range of mean root coverage from $86 \%$ to $99 \% .{ }^{11-14}$ A meta-analysis comparing the efficacy of Alloderm to other methods concluded that it could be effectively used as donor material for root coverage procedures and augmentation of keratinized gingiva. 15 The aim of this case report is to evaluate the clinical effectiveness of Alloderm in treatment of multiple gingival recession defects.

\section{Case presentation}

A healthy 23-year-old male patient reported to the clinic with the chief complaint of receding gum and hypersensitivity in lower anterior teeth. The patient's medical and dental histories were not contributory. Upon examination, Miller's class-I recession defect was found in teeth \#31, 32, 41 and 42 (Figure 1). Prior to therapy, clinical measurements including probing depth, recession depth, clinical attachment level (CAL) were obtained using a William's periodontal probe. The clinical findings are shown in Table 1.

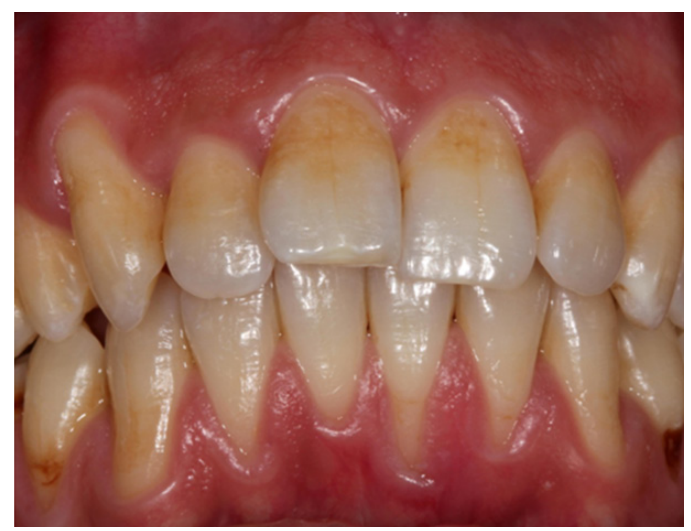

Figure I Preoperative photograph of teeth \#3I, 32, 4I and 42.

Table I Presurgical clinical findings ( $\mathrm{mm}$ )

\begin{tabular}{lllll}
\hline \multicolumn{5}{c}{ Teeth number } \\
& 31 & 32 & 41 & 42 \\
\hline Recession Depth & 4 & 2 & I & I \\
Probing Depth & I & 1 & I & 1 \\
CAL & 5 & 3 & 2 & 2 \\
\hline
\end{tabular}

CAL clinical attachment level

\section{Surgical procedure}

Preoperative intra-oral antisepsis was done using $0.12 \%$ chlorhexidine digluconate solution (rinsed for $1 \mathrm{~min}$ ). Following administration of local anesthesia, intrasulcular incision was made in 
the buccal area of the affected teeth and horizontal incisions at the level of cemento-enamel junction. A split thickness flap was extended apically in order to facilitate its coronal advancement (Figure 2). The epithelium in the adjacent papillae was de-epithelized, followed by scaling of the roots surfaces using Gracey curettes. The Alloderm was hydrated in sterile saline, according to the manufacturer's instructions. Then, it was trimmed to a shape and size designed to cover the root surface up to cementoenamel junction and extended apically beyond defect area by at least $3 \mathrm{~mm}$ (Figure 3). The Alloderm was placed with its connective tissue side towards the flap and basement membrane side towards the roots. Then, it was sutured over the defect with 5-0 bioabsorbable sutures. The flap was coronally positioned to completely cover the Alloderm and sutured using a sling suture technique by using 4-0 bioabsorbable sutures (Figure 4).

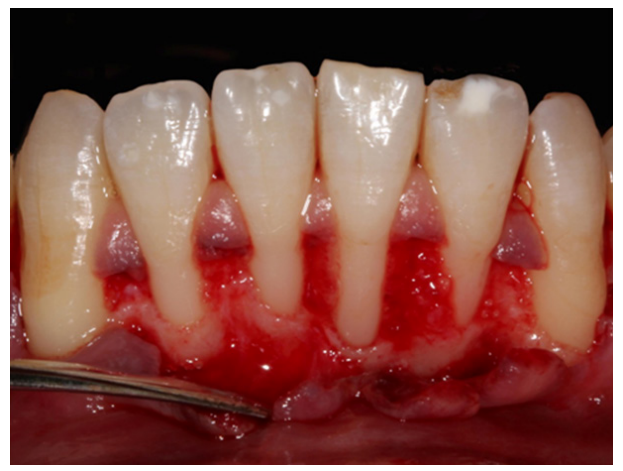

Figure 2 A flap reflection extended apically.

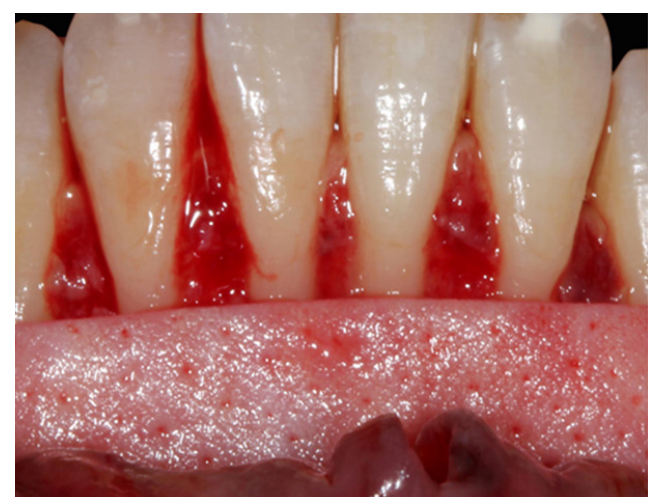

Figure 3 Alloderm is adjusted to cover the exposed root surface and surrounding bone.

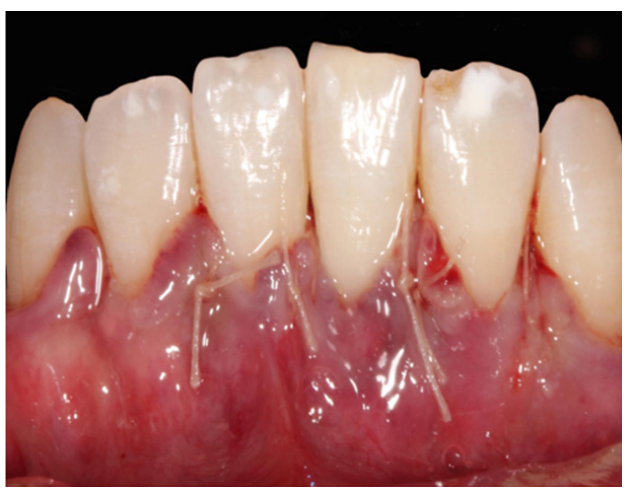

Figure 4 Gingival flap is coronally positioned to completely cover the alloderm.

\section{Post surgical care}

Immediately after surgery periodontal dressing was placed to protect the wound. The patient was instructed to discontinue tooth brushing and to avoid trauma or pressure at the surgical site. Chlorhexidine digluconate $(0.12 \%)$ mouth rinse was prescribed 2 times daily for 14 days. The patient was recalled after one week and checked for healing. The sutures were removed after 14 days (Figure 5 ) and the patient was instructed to clean the surgical sites with a cotton pellet soaked in $0.12 \%$ chlorhexidine digluconate solution 3 times daily for 10 days. After this period, the patient was asked to resume mechanical tooth cleaning of the treated areas using a soft toothbrush with modified Stillman's technique.

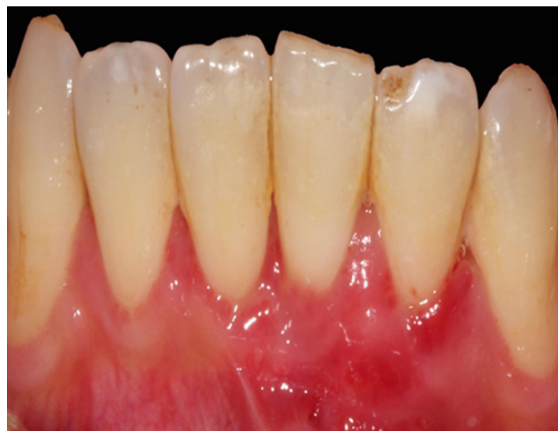

Figure 52 weeks postsurgery, complete coverage of recession defects.

\section{Clinical evaluation}

The healing process was uneventful, and the patient did not report pain or discomfort during the overall post-operative period. The grafted area healed well and almost $100 \%$ root coverage was achieved with excellent color blend. After 3 months, the Alloderm resulted in an adequate increase in the amount of attached gingiva (Figure 6). Postsurgical clinical measurements including probing depth, recession depth, CAL were obtained using a William's periodontal probe. The clinical findings are shown in Table 2.

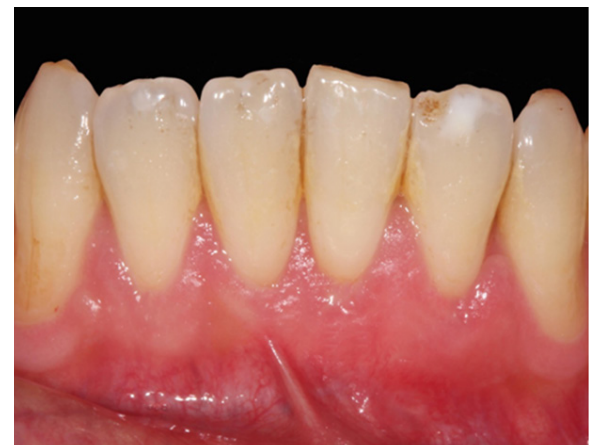

Figure 63 months postsurgey, complete coverage of recession defects.

Table 2 Postsurgical clinical findings ( $\mathrm{mm}$ )

\begin{tabular}{lllll}
\hline & \multicolumn{5}{l}{ Teeth number } \\
& 31 & 32 & 41 & 42 \\
\hline Recession Depth & 0 & 0 & 0 & 0 \\
Probing Depth & 2 & 1 & 1 & 1 \\
CAL & - & - & - & -
\end{tabular}

CAL clinical attachment level 


\section{Discussion}

In this case report, Alloderm was used in the treatment of multiple gingival recession defects. The result obtained from this study indicated that Alloderm with coronally positioned flap can be successfully used to treat periodontal recession defects. Longitudinal studies have shown a high success rate and predictability with sub epithelial graft procedure. ${ }^{16-18}$ However, autografts require a second surgical site for the donor tissue which increases the risk of pain and hemorrhage during the postoperative period. With the availability of an alternative allograft, the need for a second surgical area can be avoided. The use of Alloderm has been shown to be effective for root coverage procedure and can be used as a substitute for connective tissue grafts. ${ }^{19-21}$ It has been observed that the root coverage results obtained with Alloderm were predictable, esthetic, and stable over a long period of time. ${ }^{11}$ A Recent systematic review concluded that there were no significant differences between Alloderm and connective tissue graft with coronally advanced flap for recession coverage. ${ }^{22} \mathrm{~A}$ Human histological study revealed that both subepithelial connective tissue graft and Alloderm were well incorporated in to the recipient tissues with new fibroblasts, vascular elements, and collagen. The gingival attachment was comparable for both grafts which is a combination of long junctional epithelium and connective tissue adhesion..$^{23}$ At 3 months there was an adequate increase of keratinized tissues at the treated area. Several studies concluded that Alloderm was effectively used in increasing the width of attached gingiva and could be used as a substitute for free gingival graft. ${ }^{9-24}$ However, it was observed that Alloderm was not as predictable as free gingival autograft in terms of increasing attached keratinized tissue, due to considerable shrinkage of the Alloderm and inconsistent quality of the attached gingiva gained after therapy. ${ }^{8}$ The mechanism by which Alloderm results in an increased width of keratinized gingiva is still unknown. It is predicted that following mucogingival surgery, underlying connective tissues from gingiva and periodontal ligament possess the capacity of inducing the development of keratinized epithelium. ${ }^{25}$ Alloderm may acts as a scaffold to allow repopulation of fibroblasts, blood vessels, and epithelium from surrounding tissues, and eventually it gets completely replaced with host tissues. ${ }^{26}$

\section{Conclusion}

This case report demonstrated that Alloderm with coronally positioned flap can be successfully used in the management of multiple gingival recession defects. Alloderm is considered as a substitute for a soft tissue autografts for root coverage and gingival augmentation procedures.

\section{Acknowledgements}

None.

\section{Conflicts of interest}

None.

\section{Patient consent form}

A consent form was obtained from the patient authorizing the release of his information and photos for publication and education purposes.

\section{References}

1. Zucchelli G, De Sanctis M. Treatment of multiple recession-type defects in patients with esthetics demands. J Periodontol. 200;71(9):1506-1514.

2. Mathur RM, Chawla TN, Kapoor KK, et al. A study of gingival recession as related to oral cleaning habits. J Indian Dent Assoc. 1969;41(6):159-162.

3. Gottlow J, Karring T, Nyman S. Guided tissue regeneration following treatment of recession type defects in monkeys. $J$ Periodontol. 1990;61(11):680-685.

4. Sullivan HC, Atkins JH. Free autogenous gingival grafts I. Principles of successful grafting. Periodontics. 1968;6(3):121-129.

5. Miller PD. Root coverage using the free soft tissue autograft following citric acid application part III. A successful and predictable procedure in areas of deep wide recession. Int J Periodontics Restorative Dent. $1985 ; 5(2): 14-37$.

6. Grupe H, Warren R. Repair of gingival defects by sliding flaps operation J Periodontal. 1956;2(27):290-295.

7. Langer B, Langer L. Subepithelial connective tissue graft technique for root coverage. J Periodontal. 1985;56(12):715-720.

8. Wei PC, Laurell L, Geivelis M, et al. Acellular dermal matrix allografts to achieve increased attached gingiva. Part 1. A clinical study. J Periodontol. 200;71(8):1297-305.

9. Callan DP, Silverstein LH. Use of acellular dermal matrix for increasing keratinized tissue around teeth and implants. Pract Periodontics Aesthet Dent. 1998;10(6):731-734.

10. Shulman J. Clinical evaluation of an acellular dermal allograft for increasing the zone of attached gingiva. Pract Periodontics Aesthet Dent. 1996;8(2): 201-208.

11. Harris RJ. Acellular dermal matrix used for root coverage: 18-month follow-up observation. Int J Periodontics Restorative Dent. 2002; 22(2):156-163.

12. Henderson RD, Greenwell H, Drisko C. Predictable multiple site root coverage using an acellular dermal matrix allograft. J Periodontol. 2001;72(5):571-582.

13. Hirsch A, Goldstein M, Goultschin J, et al. A 2-year Follow-up of root coverage using subpedicle acellular dermal matrix allograft and subepithelial connective tissue graft autograft. $J$ Periodontol. 2005;76(8):1323-1328.

14. Woodyard JG, Greenwell H, Hill M, et al. The clinical effect of acellular dermal matrix on gingival thickness and root coverage compared to coronally positioned flap alone. J Periodontol. 2004;75(1): 44-56.

15. Gapski R, Parks CA, Wang HL. Acellular dermal matrix for mucogingival surgery: a meta-analysis. J Periodontol. 2005;76(11): 1814-1822.

16. Raetzke PB. Covering localized areas of root exposure employing the "envelope" technique. J Periodontol. 1985;56(7):397-402.

17. Nelson SW. The subpedicle connective tissue graft. A bilaminar reconstructive procedure for the coverage of denuded root surfaces. $J$ Periodontol. 1987;58(2):95-102.

18. Bouchard P, Etienne D, Ouhayoun JP, et al. Subepithelial connective tissue grafts in the treatment of gingival recessions. A comparative study of 2 procedures. J Periodontol. 1994;65(10):929-936.

19. Harris RJ. Root coverage with a connective tissue with partial thickness double pedicle graft and an acellular dermal matrix: A clinical and histlogical evaluation of a case report. J Periodontal. 1998;69(11):1305-1311. 
20. Aichelmann Reidy ME, Yukna RA, Mayer ET. Acellular dermal matrix used for root coverage. J Periodontal. 1999'72(8):998-1005.

21. Harris RJ. A comparative study of root coverage obtained with an acelluar dermal matrix versus a connective tissue graft. Results of 107 recession defects in 50 consecutively treated patients. Int J Periodontics Restorative Dent. 2000;20(1):51-59.

22. Gayathri GV, Choudary S, Bharath N, et al. Treatment of gingival recession with coronally advanced flap combined with connective tissue graft/ alloderm: A systematic review. Int J Oral Health Sci. 2014;4(2):70-80.

23. Cummings LC, Kaldahl WB, Allen EP. Histologic evaluation ofautogenous connective tissue and acellular dermal matrix graft in humans. J Periodontol .2005;76(2):178-186.
24. Harris RJ. Gingival augmentation with an acellular dermal matrix: Human histologic evaluation of a case - Placement of the graft on bone. Int J Periodontics Restorative Dent. 2001;24(4):378-385.

25. Karring T, Lang NP, Loe $\mathrm{H}$. The role of gingival connective tissue in determining epithelial differentiation. J Dent Res. 1972;10(1): 1-11.

26. Wei PC, Laurell L, Lingen MW, et al. Acellular dermal matrix allografts to achieve increased attached gingiva. Part 2. A histological comparative study. J Periodontol. 2002;73(3): 257-265. 